\title{
Machine Learning Aided Discovery of the Layered Double Hydroxides with the Largest Basal Spacing for Super- Capacitors
}

\author{
Kailiang L $u^{1}$, Dongping Chang ${ }^{1}$, Xiaobo $\mathrm{Ji}^{2}$, Minjie Li ${ }^{2, *}$, Wencong $\mathrm{Lu}{ }^{1,2, *}$ \\ ${ }^{1}$ Materials Genome Institute, Shanghai University, Shanghai 200444, China \\ ${ }^{2}$ Department of Chemistry, College of Sciences, Shanghai University, Shanghai 200444, China \\ *E-mail: wclu@shu.edu.cn
}

Received: 29 July 2021 / Accepted: 12 September 2021 / Published: 10 October 2021

Super capacitors with layered double hydroxides (LDHs) have excellent specific capacitance and cycling performance due to their unique layered structures and rich REDOX sites. The basal spacing $\left(d_{\text {spacing }}\right)$ of LDHs can be controlled by selecting optimal metal cations and interlayer anions. In general, the greater the $d_{\text {spacing }}$ of LDHs electrode materials, the greater the specific capacitance of the super-capacitors. In this work, the machine learning model was utilized to seek for novel LDHs materials with the larger $d_{\text {spacing. }}$ The genetic algorithm combined machine learning approaches were utilized to select the appropriate feature subset including atomic parameters and chemical compositions of LDHs. The Extreme Gradient Boosting model was established to predict the $d_{\text {spacing }}$ of LDHs. The correlation coefficient between predicted $d_{\text {spacing }}$ and experimental $d_{\text {spacing }}$ reached as high as 0.94 for the training set in leave-one-out cross-validation (LOOCV) and 0.89 for the independent testing set, respectively. The high-throughput screening of new LDHs with larger $d_{\text {spacing }}$ was carried out by using our online computation platform for materials data mining (OCPMDM). The $d_{\text {spacing }}$ of designed LDHs $\left(\mathrm{Co}_{0.67} \mathrm{Fe}_{0.33}\left[\mathrm{Fe}(\mathrm{CN})_{6}\right]_{0.11} \bullet(\mathrm{OH})_{2}\right)$ was predicted to be $12.40 \AA$, increasing by $10.91 \%$ compared to the maximum $d_{\text {spacing }}(11.18 \AA)$ of $\mathrm{Mg}_{0.67} \mathrm{Al}_{0.33}\left[\mathrm{Fe}(\mathrm{CN})_{6}\right]_{0.08} \bullet(\mathrm{OH})_{2}$ reported. The online platform for predicting $d_{\text {spacing }}$ of unknown LDHs can be accessible for the public on the web server: http://materialsdata-mining.com/online_model/LDHs_basal_spacing_model.

Keywords: Layered double hydroxides; Basal spacing; Machine learning; High-throughput screening; Material design

\section{$\underline{\text { FULL TEXT }}$}

(C) 2021 The Authors. Published by ESG (www.electrochemsci.org). This article is an open access article distributed under the terms and conditions of the Creative Commons Attribution license (http://creativecommons.org/licenses/by/4.0/). 